\title{
Effect of aspirin and other non-steroidal anti-inflammatory drugs on prostate cancer incidence and mortality: a systematic review and meta-analysis
}

\author{
Yanqiong Liu', Jun-Qiang Chen², Li Xie ${ }^{1}$, Jian Wang ${ }^{1}$, Taijie Li ${ }^{1}$, Yu He${ }^{1}$, Yong Gao ${ }^{3}$, Xue Qin ${ }^{1 *}$ and Shan $\mathrm{Li}^{1}$
}

\begin{abstract}
Background: It has been postulated that non-steroidal anti-inflammatory drugs (NSAIDs) use leads to decreased prostate cancer (PCa) risk. In recent years, NSAIDs' role in PCa development has been extensively studied; however, there is not yet a definitive answer. Moreover, the epidemiological results for NSAIDs' effect on PCa-specific mortality have been inconsistent. Therefore, we performed a meta-analysis to examine the controversy.

Methods: We performed a literature database search and included all published studies conducted in the general population exposed to any NSAID, extracting an odds ratio (OR) or a hazard ratio (HR) with 95\% confidence intervals $(95 \% \mathrm{Cls})$ that compared the incidence of PCa or PCa-specific mortality with non-exposure. We derived a pooled OR or HR using random or fixed effects models, as appropriate. Subgroup analyses were also performed.

Results: Thirty-nine studies (20 case-control and 19 cohort studies) were included in this analysis. Thirty-one studies were available concerning NSAID use and PCa incidence and eight studies on PCa-specific mortality. Compared to non-use, aspirin use was statistically significantly associated with PCa incidence risk, and the association was slightly stronger for advanced PCa than for total PCa $(\mathrm{OR}=0.92,95 \% \mathrm{Cl}=0.87$ to 0.97 for total $\mathrm{PCa}$; $\mathrm{OR}=0.81,95 \%$ $\mathrm{Cl}=0.73$ to 0.89 for advanced P(a). Aspirin use seems also to be associated with a modest reduction in PCa-specific mortality ( $\mathrm{HR}=0.86,95 \% \mathrm{Cl}=0.78$ to 0.96 for total $\mathrm{PCa} ; \mathrm{OR}=0.81,95 \% \mathrm{Cl}=0.71$ to 0.92 for advanced $\mathrm{PCa}$ ). Generally, the pooled effects for any NSAIDs, NA-NSAIDs and cyclooxygenase-2 inhibitors demonstrated no adverse or beneficial effects on PCa development or PCa-specific mortality, but the results were not consistent. The effect estimates did not vary markedly when stratified by study design and study quality but varied by geographic region. Furthermore, long-term aspirin use ( $\geq 4$ years) was also significantly associated with reduced PCa incidence ( $\mathrm{OR}=0.88,95 \% \mathrm{Cl} 0.79$ to 0.99$)$.
\end{abstract}

Conclusions: The present meta-analysis provides support for the hypothesis that aspirin use is inversely related to PCa incidence and PCa-specific mortality. The effect estimates, varying by geographic region, deserve further investigation.

Keywords: Aspirin, NSAID, Prostate cancer, Incidence, Mortality

\section{Background}

Prostate cancer $(\mathrm{PCa})$ is one of the most frequently occurring cancers and cause of cancer-related deaths in men [1]. According to the latest report from the American Cancer Society, in 2014, 233,000 new cases will be diagnosed, and 29,480 estimated deaths from PCa are predicted

\footnotetext{
*Correspondence: qinxue919@126.com

'Department of Clinical Laboratory, First Affiliated Hospital of Guangxi Medical University, Nanning, Guangxi Zhuang Autonomous Region, China Full list of author information is available at the end of the article
}

in the United States [1]. Although the five-year relative survival rate has increased over the past 25 years [2], PCa is still the leading cause of cancer death in older men [1]. There is an urgent need for a better understanding of the factors related to $\mathrm{PCa}$ development and prognosis.

Cyclooxygenase-2 (COX-2), an inducible enzyme, is overexpressed in $\mathrm{PCa}$ tissue [3] and plays a role in $\mathrm{PCa}$ cell growth [4]. Aberrant or high expression of COX-2 has been implicated in carcinogenesis and poorer prognosis $[5,6]$. Therefore, it has been speculated that non-steroidal 
anti-inflammatory drugs (NSAIDs), which inhibit the COX pathway, may provide a strategy for mechanistically based PCa chemoprevention and therapy [3]. Indeed, a number of epidemiologic studies have investigated the association between NSAID use and the risk of PCa but showed conflicting results, with the majority finding null effects [7-22], some reporting statistically significant inverse associations [23-34] and a minority reporting a significantly elevated risk of prostate cancer in association with NSAID or non-aspirin NSAID (NA-NSAID) use [35-37]. In a study conducted by Mahmud et al. [38], which searched databases in June 2008, the association of the use of aspirin and other NSAIDs with PCa incidence was suggestive but not conclusive. Several observational studies published after this meta-analysis have shown contrasting results [19-22,32-34,36,37], which has added new evidence to the previous research. On the other hand, since considerable evidence implies that aspirin use may reduce the risk of $\mathrm{PCa}$, a better understanding of whether such therapy can influence disease outcome is important and necessary. To date, several studies have examined NSAID (aspirin) use and $\mathrm{PCa}$-specific mortality, and these have reported conflicting findings [39-46].

Given widespread and long-term NSAID use, more knowledge is needed to clarify the drugs' role in PCa incidence and mortality. Therefore, we performed a comprehensive review and provide a quantitative assessment of all relevant published studies to understand this issue better. A better understanding of the relationship may also highlight the importance of considering additional prevention methods in this area.

\section{Methods}

\section{Data sources and searches}

This study was performed according to the Preferred Reporting Items for Systematic Reviews and Meta-Analyses (PRISMA) checklist [see Additional file 1] [47]. Three authors (YL, JC and LX) experienced in Cochrane review searched electronic databases for articles published through 29 December 2013. The databases included PubMed, Embase, ISI Web of Science and the WHO Library Database. The search terms included the therapeutic classes, generic names of individual drugs and PCa outcome terms [see Additional file 2]. No language restrictions were imposed. Additional studies were searched for manually through the reference lists of retrieved articles and using PubMed's related articles option.

\section{Eligibility criteria and study selection}

To be included, studies had to meet the following criteria: (1) studied participants were exposed to any NSAID, including aspirin, NA-NSAIDs, any other single NSAID (not including acetaminophen) or a mixture of NSAIDs or selective COX-2 inhibitors and reference participants had not used these drugs; (2) the study assessed the incidence of PCa or PCa-specific mortality; and (3) the study reported the multivariate-adjusted relative risks (RRs), including study-specific odds ratios (ORs) or hazard ratios (HRs) and 95\% confidence intervals (CIs). No study design restrictions were imposed. Reviews, letters, comments, lectures and case reports were all excluded. When study populations overlapped, only the study of larger size or the most informative one was included. However, if overlapping studies offered additional information for subgroup analysis that could not be extracted from the primary studies, they were included in the subgroup analysis. Two authors (JW, TL) independently evaluated all records by title and abstract and subsequently retrieved and assessed in detail the full text of any potentially relevant articles according to the eligibility criteria. Disagreements or uncertainties regarding eligibility were resolved through discussion with two additional adjudicators (XQ, SL).

\section{Data extraction and quality assessment}

For each trial, the study and participant characteristics, number of cases and controls, drug types, exposure period and multivariable adjusted RR estimates with corresponding 95\% CIs were extracted and transferred to specially designed forms. If the required data for the meta-analysis were not readily available in the published article, the principal author was contacted at least once. Data were obtained and independently reviewed by two reviewers ( $\mathrm{YL}$ and $\mathrm{SL}$ ), and the final decision was reached by consensus. The methodological quality of observational studies was assessed by two authors (XQ and YL) independently using the Newcastle-Ottawa scale (NOS) [48]. Disagreement was resolved by consensus. In this scale, studies are awarded a maximum score of 9 points; a high-quality study is awarded $\geq 7$ points, a medium-quality study between 4 and 6 points and a poor-quality study $<4$ points.

\section{Data synthesis and statistical analysis}

We evaluated the association of NSAID use with two endpoints: (1) the OR of PCa incidence and (2) the HRs of PCa-specific mortality. Pooled ORs and HRs with 95\% CI were obtained using a fixed effects model [49] or the random effects model of DerSimonian and Laird [50] if needed due to between-study heterogeneity. Because the evaluated outcomes are relatively rare and the effects estimated are generally small, ORs in case-control studies were considered reasonable approximations of the corresponding risk ratios in cohort studies [51], permitting the combination of cohort and case-control studies. Inter-study heterogeneity was tested by Cochran's Q test [52] and quantified by the $I^{2}$ statistics [53]. For the Q statistic, a $P$ value $<0.10$ was considered statistically significant for heterogeneity; for $I^{2}$, a value $>50 \%$ indicates a measure of heterogeneity [52]. Cumulative meta-analysis 
was conducted to examine how the evidence has changed over time. We assessed publication bias graphically using a funnel plot and quantitatively using the Begg rank correlation test and the Egger regression asymmetry test $[54,55]$ where numbers of studies allowed ( $>10$ studies). Sensitivity analyses were also conducted to assess the robustness of the results by the sequential omission of individual studies [56].

To detect potential interactions, studies were stratified by the type of medicine (NSAIDs overall, aspirin, NA-NSAIDs and COX-2 inhibitors) and study outcome (total PCa (all cancers regardless of stage), advanced cancers (lesions with extracapsular extension or metastases to regional lymph nodes or other organs) and non-advanced cancers). Further subgroup analysis estimated the effects of NSAIDs on PCa risk by study design, studies defined as high quality, geographic region and duration of aspirin use. A two-tailed $P$ value $<0.05$ was considered statistically significant. All analyses were performed using STATA version 12.0 (StataCorp, College Station, TX, USA).

\section{Results}

Study selection, characteristics and quality

Our initial search identified 4,331 studies, of which we obtained 51 full-text articles, and 39 studies [7-37,39-46] were included in the review. References for studies excluded from the full-text study review process and the additional records identified through a manual review are listed in Additional file 3. A PRISMA trial flow diagram for systematic review is presented in Figure 1. One article from the Cancer Prevention Study II Nutrition Cohort by Jacobs et al. [18] in 2007 was excluded from the primary outcome analysis because this article only updated the duration-effect of aspirin contrasting the primary group [14]; therefore, the study data were re-entered for subgroup analyses for duration of aspirin.

The studies that met the inclusion criteria were all observational studies, comprising 20 case-control [9-11,16,17,21-23,26,28-33,35-37,41,44] and 19 cohort studies $[7,8,12-15,18-20,24,25,27,34,39,40,42,43,45,46]$ involving more than 924,502 male subjects, including $108,136 \mathrm{PCa}$ cases. Thirty-one studies (18 casecontrol [9-11,16,17,21-23,26,28-33,35-37] and 13 cohort $[7,8,12-15,18-20,24,25,27,34])$ addressed the use of any NSAID and its association with $\mathrm{PCa}$ incidence risk (Table 1); eight studies (two case-control [41,44] and six cohort $[39,40,42,43,45,46])$ investigated whether NSAID use was associated with PCa-specific mortality (Table 2). For NSAID use and PCa incidence risk, the publication dates of the studies ranged between 1989 and 2014. A majority of the studies were conducted in North America (16 in the USA and four in Canada) and 10 in Europe. For NSAID use and PCa-specific mortality, five studies $[39-41,43,45]$ measured exposure to aspirin, one study [44] addressed any NSAIDs, one study [46] covered only NANSAIDs, and one study [42] employed all three categories.

With regard to the quality of all the included studies assessed by NOS (Table 1 and Table 2), 18 studies (46.2\%) were graded as having good quality (seven or more points), $20(51.3 \%)$ were graded as medium-quality (four to six points), and one study (2.5\%) conducted in 1989 was graded as poor-quality (three points). The details of the quality assessment are presented in Additional file 4.

\section{Association between the use of any NSAID and the incidence of prostate cancer}

Eleven studies (eight case-controls and three cohorts) evaluated exposure to any NSAIDs and the incidence of total $\mathrm{PCa}$, and five studies examined the effect of any NSAIDs on the incidence of advanced PCa, but no studies examined non-advanced PCa. Figure 2 shows the studyspecific and pooled ORs and 95\% CIs of PCa for any NSAID users versus non-NSAID users. The summary OR for the 11 studies that assessed the effect of any NSAIDs on total PCa was 0.90 (95\% CI: 0.75 to $1.07 ; I^{2}=93.5 \%$ ). The effect estimates were similar for five studies on any NSAIDs and advanced $\mathrm{PCa}(\mathrm{OR}=0.86,95 \% \mathrm{CI}: 0.52$ to 1.40$)$ (Figure 2, Table 3). These analyses yielded substantial heterogeneity $\left(I^{2}=93.5 \%\right.$ and $I^{2}=94.2 \%$, respectively) and revealed that any NSAIDs were not associated with a significant decrease in the incidence of $\mathrm{PCa}$.

In sensitivity analyses, none of the individual studies substantially altered the pooled ORs for any NSAIDs on total $\mathrm{PCa}$, which varied from 0.86 (95\% CI, 0.71 to 1.04 ) to 0.96 ( $95 \% \mathrm{CI}, 0.81$ to 1.14 ). The direction and magnitude of the negative effect did not vary markedly when stratified by study design (Table 3). However, when we combined studies by geographic region, the six studies from North America had a summary OR of 0.73 (95\% CI: 0.60 to 0.88 ; $P_{O R}=0.001 ; I^{2}=79.6 \%$ ), whereas the other five studies from Europe had a higher and statistically significant summary OR of 1.29 (95\% CI: 1.25 to $1.34 ; P_{O R}<0.001 ; I^{2}=37.2 \%$ ) (Table 3).

For publication bias assessment, the inverted funnel plot was potentially asymmetric, and the results of the Begg test $(P=0.350)$ and the Egger test $(P=0.037)$ implied some evidence of publication bias (Figure $3 \mathrm{~A})$.

\section{Association between aspirin use and PCa incidence}

Twenty-three studies, thirteen studies, and six studies evaluated exposure to aspirin and the incidence of total $\mathrm{PCa}$, advanced $\mathrm{PCa}$, and non-advanced $\mathrm{PCa}$, respectively. Figure 4 graphs the ORs and 95\% CIs from the individual studies and the pooled results. The 23 studies that assessed the effect of aspirin on total PCa showed an inverse association $(\mathrm{OR}=0.92,95 \% \mathrm{CI}: 0.87$ to 0.97$)$ and were moderately heterogeneous $\left(I^{2}=66.2 \%, P<0.001\right)$. The 13 studies of advanced PCa were consistent; the risk decrease 


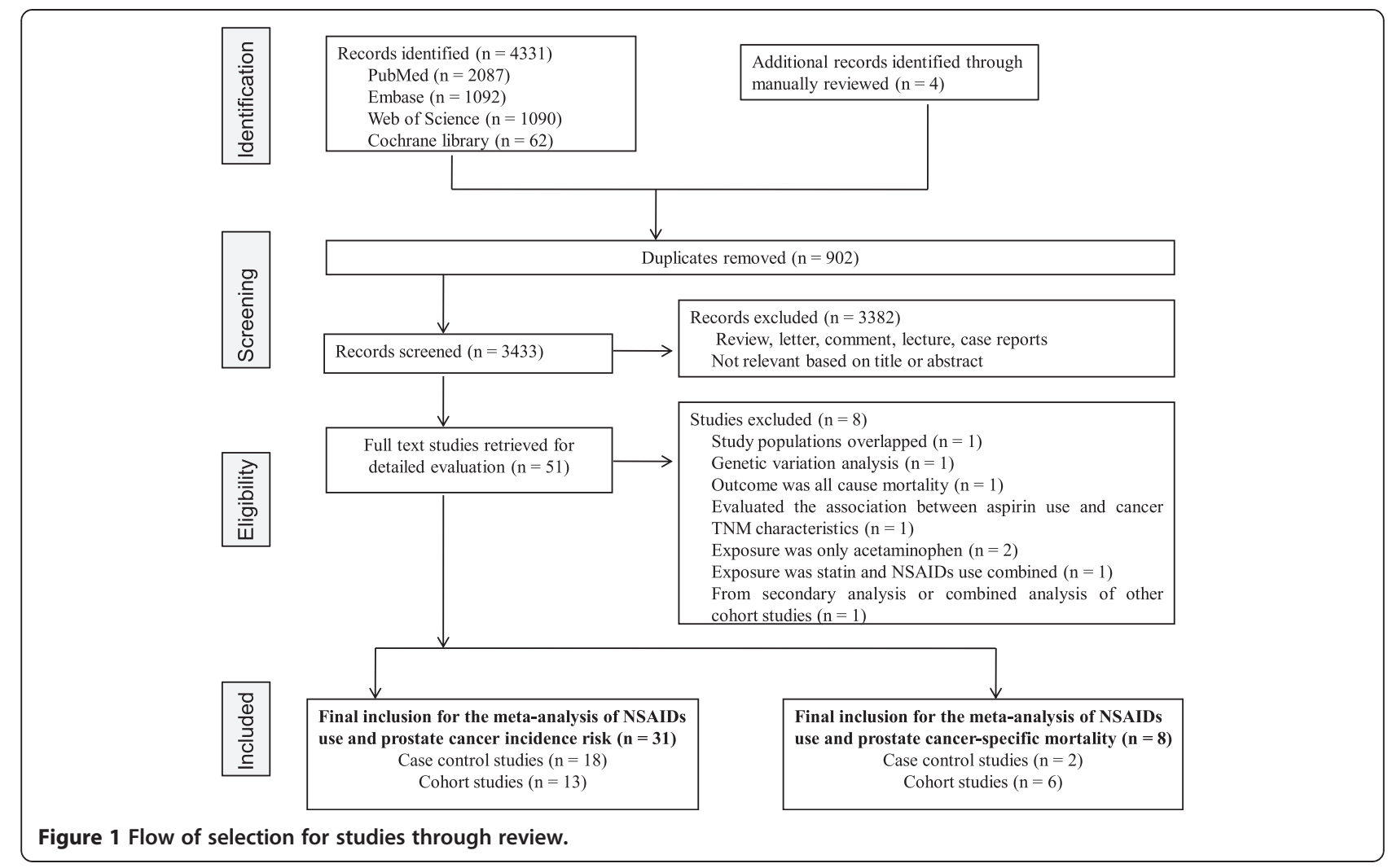

persisted and was slightly lower than for the total PCa (OR $=0.81,95 \% \mathrm{CI}: 0.73$ to $\left.0.89 ; I^{2}=23.9 \%\right)$. However, a non-significant decreased risk was observed in nonadvanced $\mathrm{PCa}(\mathrm{OR}=0.96,95 \% \mathrm{CI}: 0.87$ to 1.07$)$, with little evidence of heterogeneity $\left(I^{2}=34.6 \%, P=0.177\right)$.

We saw no evidence of obvious influential studies in sensitivity analyses by the sequential omission of individual studies. The summary ORs for total cancer were reasonably stable, ranging from 0.91 when the study by Friis et al. [12] was excluded to 0.94 when the study by Rodriguez et al. [27] was excluded. Table 3 shows the results of the subgroup analyses. The risk decrease persisted for both total and advanced PCa when the data were stratified into subgroups based on study design and study quality. The effect sizes showed moderate statistical heterogeneity among studies of total PCa but no heterogeneity among studies of advanced PCa. Adjustment for geographic region had the strongest influence on the summary $\mathrm{OR}$, demonstrating negative results.

We examined the association between long-term aspirin use (defined as ever use of aspirin for more than four years) and risk of total $\mathrm{PCa}$ incidence using the data available from the included studies. Eight studies [15,17-20,26,27,32] were included in this analysis. The pooled results slightly strengthened the association of aspirin use with total $\mathrm{PCa}$ (OR: 0.88, 95\% CI: 0.79, 0.99) (see Table 3 and Additional file 5: Figure S1). Most studies lacked information on the dose and frequency of aspirin use, or the information varied in each trial; hence, a statistical analysis of significance between these groups was not valid.

A visual inspection of the funnel plot found no evidence of publication bias (Figure 3B). The $P$ values for the Begg test and the Egger test were $P=0.316$ and $P=0.273$, respectively, both suggesting a very low probability of publication bias.

A cumulative meta-analysis of a total of 23 studies of total PCa was carried out to evaluate the cumulative effect estimate over time. In 1989, Paganini-Hill et al. [7] first reported a non-significant effect estimate of 0.95. Between 1994 and 2006, 14 studies were published, with a cumulative OR of 0.89 ( $95 \%$ CI: 0.81 to 0.98 ). A statistically significant effect of aspirin use on PCa incidence was consistently observed after publication of the 13th trial in 2006. Between 2007 and 2013, eight more publications were added cumulatively, resulting in an overall effect estimate of 0.92 (95\% CI 0.87 to 0.97) [see Additional file 5: Figure S2].

\section{Association between NA-NSAID use and PCa incidence}

Seventeen studies, nine studies, and three studies evaluated exposure to NA-NSAID and the incidence of total PCa, advanced $\mathrm{PCa}$, and non-advanced $\mathrm{PCa}$, respectively. Figure 5 illustrates the ORs and 95\% CIs from the individual studies and the pooled results. The meta-analysis revealed that NA-NSAID use was not significantly associated with 
Table 1 Characteristics of included studies: any NSAIDs use and PCa incidence risk

\begin{tabular}{|c|c|c|c|c|c|c|c|c|c|c|}
\hline Study & $\begin{array}{l}\text { Study } \\
\text { location }\end{array}$ & $\begin{array}{c}\text { Cases } \\
\text { (number) }\end{array}$ & $\begin{array}{l}\text { Controls } \\
\text { (number) }\end{array}$ & Age $(y)^{a}$ & $\begin{array}{l}\text { Exposure } \\
\text { period }\end{array}$ & Drugs studied & Outcome (number) & $\begin{array}{l}\text { Information } \\
\text { source }\end{array}$ & $\begin{array}{l}\text { Confounders } \\
\text { for adjustment }\end{array}$ & $\begin{array}{c}\text { Quality } \\
\text { score }\end{array}$ \\
\hline \multicolumn{11}{|l|}{ Case-control studies } \\
\hline Veitonmaki, 2013 [37] & Finland & 24,657 & 24,657 & 68 & 1995-2002 & $\begin{array}{l}\text { ASA/NSAIDs/ NA-NSAIDs/ } \\
\text { COX-2 inhibitors }\end{array}$ & Total/advanced PCa & Database & $1-5$ & 8 \\
\hline Kopp, 2013 [22] & Denmark & 334 & 334 & 59.0 & 1993-1997 & NSAIDs & Total PCa & Questionnaire & $1,6,7$ & 4 \\
\hline Vinogradova, 2011 [21] & UK & 14,764 & 192,081 & 69 & 1997-2008 & COX-2 inhibitors & Total PCa & Database & $1,8-11$ & 7 \\
\hline Murad, 2011 [36] & UK & 1,016 & 5,043 & 63 & $2001-2008$ & ASA/NSAIDs/ NA-NSAIDs & Total PCa & Questionnaire & $1,12-15$ & 6 \\
\hline Mahmud, 2011 [33] & Canada & 9,007 & 36,028 & 73 & 1985-2000 & ASA/NSAIDs/ NA-NSAIDs & Total PCa & Database & 1, 14-17 & 6 \\
\hline Salinas, 2010 [32] & USA & 1,001 & 942 & 63 & 2002-2005 & $\begin{array}{l}\text { ASA/NA-NSAIDs/ } \\
\text { COX-2 inhibitors }\end{array}$ & Total/advanced PCa & Questionnaire & $1,17-18$ & 7 \\
\hline Harris, 2007 [31] & USA & 229 & 285 & NR & 2002-2004 & $\begin{array}{l}\text { ASA/ NA-NSAIDs/ } \\
\text { COX-2 inhibitors }\end{array}$ & Total PCa & Interview & $1,6,19-21$ & 5 \\
\hline Menezes, 2006 [17] & USA & 1,029 & 1,029 & 67 & 1982-1998 & ASA & Total/advanced PCa & Questionnaire & $1,6,12$ & 4 \\
\hline Mahmud, 2006 [30] & Canada & 494 & 805 & 64 & 1999-2003 & $\begin{array}{l}\text { ASA/ NSAIDs/ NA-NSAIDs/ } \\
\text { COX-2 inhibitors }\end{array}$ & Total/advanced PCa & Questionnaire & $1,12,14,15,22-25$ & 6 \\
\hline Liu, 2006 [29] & USA & 506 & 506 & NR & $2001-2004$ & ASA/ NSAIDs / NA-NSAIDs & Advanced PCa & Interview & $1,18,26$ & 5 \\
\hline Dasgupta, 2006 [28] & Canada & 2,025 & 2,150 & 73 & 1999-2002 & ASA/NA-NSAIDs & Total PCa & Database & 1,27 & 6 \\
\hline Bosetti, 2006 [16] & Italy & 1,261 & 1,131 & 65 & 1991-2002 & ASA & Total/advanced PCa & Questionnaire & $1,7,12,28$ & 5 \\
\hline Perron, 2003 [26] & Canada & 2,221 & 11,105 & 75.7 & 1993-1995 & ASA/NA-NSAIDs & Total PCa & Database & 1,29 & 6 \\
\hline Irani, 2002 [11] & France & 639 & 659 & 66.8 & 1999-2000 & ASA/NA-NSAIDs & Total PCa & Questionnaire & $1,14,15,18,27,30-32$ & 6 \\
\hline Nelson, 2000 [23] & USA & 417 & 420 & 64.0 & 1992-1995 & NA-NSAIDs/ NSAIDs & Total PCa & Interview & $1,18,23$ & 6 \\
\hline Langman, 2000 [35] & UK & 1,813 & 5,354 & NR & 1993-1995 & NSAIDs & Total PCa & Database & 1,9 & 6 \\
\hline Norrish, 1998 [10] & New Zealand & 317 & 480 & 70.0 & 1996 & ASA/ NSAIDs/ NA-NSAIDs & Total/advanced PCa & Questionnaire & $1,33-36$ & 7 \\
\hline Neugut, 1998 [9] & USA & 319 & 189 & 69.0 & 1984-1986 & ASA & Total PCa & Medical notes & $1,18,13,22$ & 6 \\
\hline Cohort studies & & & $\begin{array}{l}\text { All subjects } \\
\text { (number) }\end{array}$ & & $\begin{array}{c}\text { Median } \\
\text { follow-up (y) }\end{array}$ & & & & & \\
\hline Shebl, 2012 [34] & USA & 3,573 & 29,450 & 62.8 & 11.7 & ASA/NA-NSAIDs & Total/advanced PCa & Questionnaire & $1,12,14,15,17,18,28$ & 6 \\
\hline Dhillon, 2011 [20] & USA & 4,858 & 51,529 & 64.8 & 18.0 & ASA & Total/advanced PCa & Questionnaire & $\begin{array}{c}1,4,6,9,12,18,20,31 \\
36-39\end{array}$ & 8 \\
\hline Brasky, 2010 [19] & USA & 1,550 & 34,132 & $50-76$ & NR & ASA/NA-NSAIDs & Total/advanced PCa & $\begin{array}{l}\text { Questionnaire } \\
\text { and Database }\end{array}$ & $\begin{array}{c}1,6,7,12,13,18,22 \\
39-45\end{array}$ & 5 \\
\hline Jacobs, 2007 [18] & USA & 1,076 & 69,810 & NR & $\begin{array}{c}104,854 \\
\text { person-years }\end{array}$ & ASA & Total PCa & $\begin{array}{l}\text { Questionnaire and } \\
\text { medical records }\end{array}$ & $\begin{array}{c}1,6,7,9,13,15,18,20 \\
22,45-47\end{array}$ & 7 \\
\hline Platz, 2005 [15] & USA & 141 & 1,244 & 70.0 & 9.0 & ASA/NSAIDs/ NA-NSAIDs & Total PCa & Questionnaire & $1,14,15,23,37$ & 7 \\
\hline Jacobs, 2005 [14] & USA & 4,853 & 70,144 & NR & 1992-2001 & ASA/NSAIDs/ NA-NSAIDs & Total/advanced PCa & Questionnaire & $1,7,12,13,18,22,45$ & 7 \\
\hline G-Rodriguez, 2004 [27] & UK & 2,183 & 12,183 & $50-79$ & 1995-2001 & ASA/NA-NSAIDs & Total/advanced PCa & Database & $1,14,15,17,37,48$ & 8 \\
\hline
\end{tabular}


Table 1 Characteristics of included studies: any NSAIDs use and PCa incidence risk (Continued)

\begin{tabular}{|c|c|c|c|c|c|c|c|c|c|c|}
\hline Sorensen, 2003 [13] & Denmark & 324 & 172,057 & NR & 5.4 & NA-NSAIDs & Total PCa & Database & $1,10,11$ & 7 \\
\hline Friis, 2003 [12] & Denmark & 196 & 29,470 & 70.0 & 4.1 & ASA & Total PCa & Database & $1,10,11$ & 7 \\
\hline Roberts, 2002 [25] & USA & 91 & 1,362 & 64.0 & 5.5 & NSAIDs & Total PCa & Questionnaire & $1,10,12,20$ & 7 \\
\hline Habel, 2002 [24] & USA & 2,574 & 90,100 & $18-84$ & 14.0 & ASA & Total/advanced PCa & Questionnaire & $1,7,17,18$ & 6 \\
\hline Schreinemachers, 1994 [8] & USA & 123 & 12,668 & 65.0 & 12.4 & ASA & Total PCa & Interview & $1,7,9,18,21$ & 5 \\
\hline Paganini-Hill, 1989 [7] & USA & 149 & 5106 & 73 & 6.5 & ASA & Total PCa & Questionnaire & 1 & 3 \\
\hline
\end{tabular}

average, median or range.Confounders for adjustment: 1, age; 2 , benign prostatic hyperplasia medication use; 3 , anti-diabetic medication; 4, cholesterol-lowering medication use; 5 , antihypertensive medication use; 6 , body mass index; 7 , school education; 8 , deprivation; 9 , smoking; 10 , comorbidities; 11 , use of medication; 12 , family history of prostate cancer; 13 , diabetes status; 14 , aspirin use; 15 , any NA-NSAID use; 16 , ever visited a urologist 1 to 11 years prior; 17 , screened and volume of family physician visits; 18 , race; 19 , family history; 20, physical activity; 21, alcohol intake; 22 , history of heart disease; 23 , intake of acetaminophen; 24 , reasons for referral and prostate volume; 25, selective cyclooxygenase-2 (COX-2) inhibitors use; 26, medical institution; 27, finasteride use; 28, study center; 29, recent medical contacts; 30, farming; 31, frequency of red meat and red wine consumption; 32 , urological center; 33, socio-economic status; 34 , total polyunsaturated fat consumption; 35 , a-linolenic acid; 36 , fatty acids; 37 , period; 38 , height; 39 , vitamin; 40 , osteoarthritis; 41, rheumatoid arthritis; 42, chronic joint pain; 43, chronic headaches; 44, migraines; 45, PSA test in the past two years; 46 , history of colorectal endoscopy; 47 , hypertension; 48, prior benign prostate hyperplasia history. ASA, aspirin; COX-2, cyclooxygenase enzymes-2; NA-NSAIDs, non-aspirin NSAIDs; NR, not reported; PCa, prostate cancer; y, years. 
Table 2 Characteristics of included studies: any NSAIDs use and prostate cancer-specific mortality

\begin{tabular}{|c|c|c|c|c|c|c|c|c|c|c|c|}
\hline Study & Study location & Study design & $\begin{array}{l}\text { PCa Cases } \\
\text { (number) }\end{array}$ & $\begin{array}{l}\text { Died from } \\
\text { PCa (number) }\end{array}$ & Age (y) & $\begin{array}{l}\text { Median } \\
\text { follow-up (y) }\end{array}$ & Drugs studied & Treatment & $\begin{array}{l}\text { Tumor } \\
\text { stage }\end{array}$ & $\begin{array}{l}\text { Confounders } \\
\text { for adjustment }\end{array}$ & $\begin{array}{l}\text { Quality } \\
\text { score }\end{array}$ \\
\hline Flahavan, 2014 [39] & Ireland & Cohort & 2,936 & 104 & 70.5 & 5.5 & Aspirin & $P R, R T, A D T$ & $|-|||$ & $1-8$ & 8 \\
\hline Grytli, 2014 [40] & Norway & Cohort & 3,561 & 1,010 & 76.3 & 3.3 & Aspirin & ADT & I-IV & $1,2,9-13$ & 7 \\
\hline Cardwell, 2013 [41] & UK & Nested case-control & 6,339 & 1,184 & NR & 6.0 & Aspirin & PR, RT, ADT, EST & I-IV & $1,4,8,13-17$ & 7 \\
\hline Dhillon, 2012 [42] & USA & Cohort & 3,986 & 265 & 68.6 & 8.4 & $\begin{array}{c}\text { Aspirin/NSAIDs/ } \\
\text { NA-NSAIDs }\end{array}$ & $P R, R T, E S T$ & |-||lab & $1,2,4,6,10,18-29$ & 7 \\
\hline Choe, 2012 [43] & USA & Cohort & 5,955 & 193 & 64.0 & 5.8 & Aspirin & $\mathrm{RP}, \mathrm{RT}$ & I-IV & $1,2,9,10,29-31$ & 8 \\
\hline Stock, 2008 [44] & Canada & Case-control & 1,619 & 453 & 67.2 & NR & NSAIDs & $\mathrm{RP}, \mathrm{RT}$ & I-IV & $1,2,9,21$ & 7 \\
\hline Ratnasinghe, 2004 [45] & USA & Cohort & NR & 121 & $25-74$ & NR & Aspirin & NR & NR & $1,4,19,21,32-33$ & 6 \\
\hline Lipworth, 2004 [46] & Denmark & Cohort & NR & 296 & 48.4 & 4.3 & NA-NSAIDs & NR & NR & 1,33 & 5 \\
\hline
\end{tabular}

Confounders for adjustment: 1, age; 2, tumor grade; 3, tumor size; 4, smoking status; 5, co-morbidity score; 6, year of incidence; 7, pre-diagnostic statin exposure 8, receipt of radiation; 9, prostate-specific antigen level;

10, Gleason score; 11, presence and type of metastases; 12 , performance status; 13, androgen deprivation therapy initiated within six months after diagnosis; 14 , year of cancer diagnosis; 15 , chemotherapy within six months of diagnosis; 16 , estrogen therapy during exposure period; 17 , comorbidities; 18 , family history; 19 , race; 20, height; 21 , body mass index; 22 , vigorous physical activity; 23 , vitamin $D ; 24$, fish; 25 , red meat; 26 , cholesterol-lowering drugs; 27, total kcal; 28 , aspirin use before diagnosis; 29, initial treatment; 30, aspirin use; 31, non-aspirin anticoagulant use; 32, poverty index; 33, education; 33, number of prescriptions. ADT,

androgen-deprivation therapy; EST, estrogen therapy; NA-NSAIDs, non-aspirin NSAIDs; NR: not reported; RP, radical prostatectomy; RT, radiation therapy; y, years. 


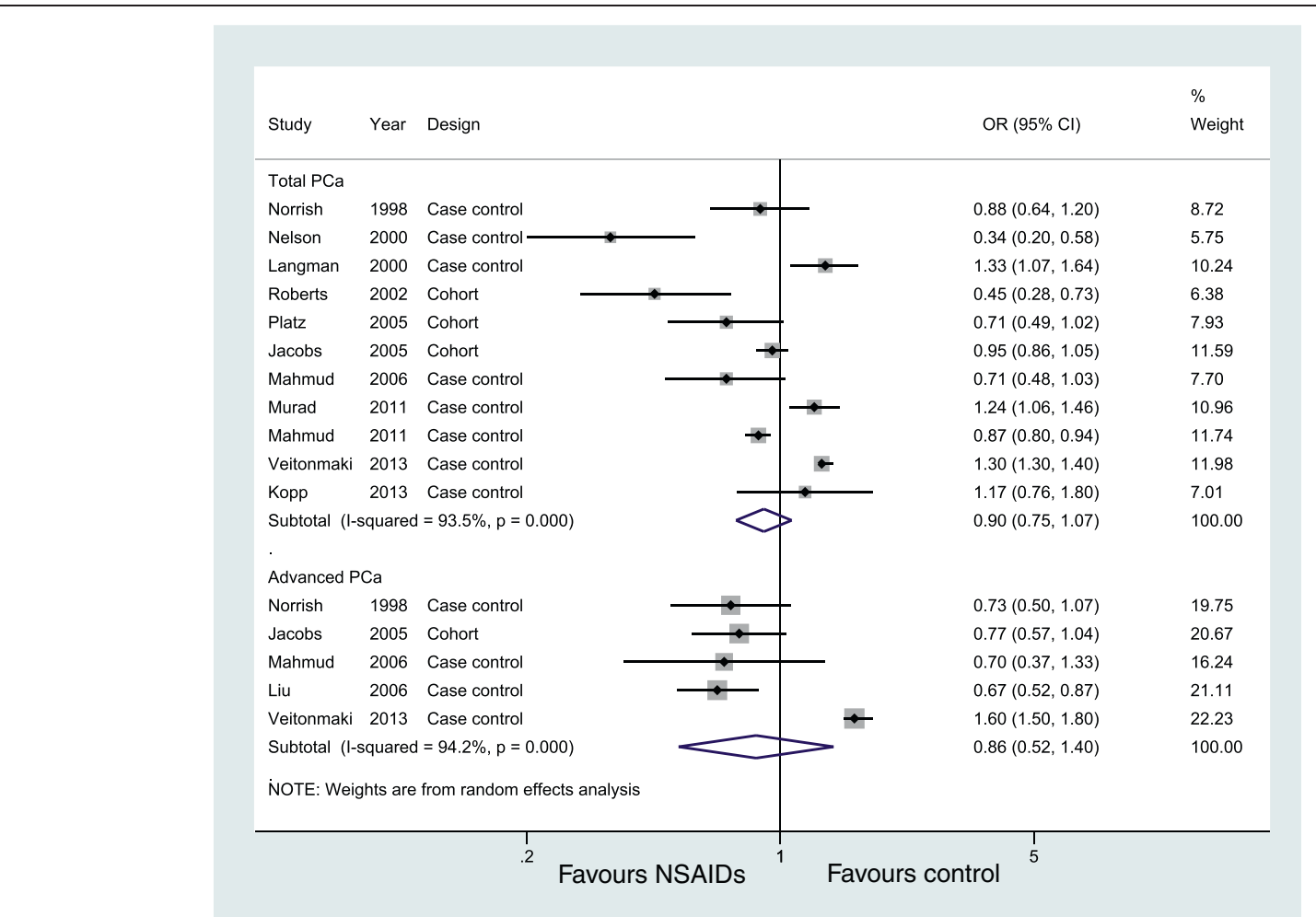

Figure 2 Association between use of any NSAIDs and incidence of prostate cancer.

the incidence of PCa (OR $=1.01,95 \% \mathrm{CI}: 0.90$ to 1.13 for total cancer; $\mathrm{OR}=0.99,95 \% \mathrm{CI}: 0.77$ to 1.28 for advanced cancer; $\mathrm{OR}=1.00,95 \% \mathrm{CI}$ : (0.90 to 1.12 for non-advanced cancer), both with substantial heterogeneity between studies except for non-advanced PCa analysis. Table 2 presents the results of subgroup analyses.

For publication bias, the funnel plot was slightly asymmetric (Figure $3 C$ ), and the $P$ values for the Begg test and the Egger test were 0.711 and 0.050 , respectively, suggesting a low probability of publication bias.

\section{Association between any COX-2 inhibitor use and PCa incidence}

Five studies [21,30-32,37] evaluated COX-2 inhibitor use and PCa risk. Overall, use of COX-2 inhibitors appeared not to be statistically significantly associated with PCa risk compared to non-use (Table 3; Additional file 5: Figure S3). For studies with small numbers, we did not perform subgroup analyses.

\section{Association between any NSAID use and PCa-specific mortality}

Eight studies [39-46] investigated exposure to any NSAIDs use (including aspirin use alone) with $\mathrm{PCa}$-specific mortality (Table 2). The pooled result shows that the use of any NSAID had a neutral influence on the PCa-specific mortality in a random effects model, with an $\mathrm{HR}=1.00$
(95\% CI: $0.68,1.47)$ but with substantial heterogeneity $\left(I^{2}=95.3 \%\right.$ ) (Table 3 and Additional file 5: Figure S4). Studies of aspirin were more consistent; the pooled results indicated that aspirin use was statistically significantly associated with a modest reduction in $\mathrm{PCa}$-specific mortality $(\mathrm{OR}=0.86,95 \% \mathrm{CI}: 0.78$ to 0.96$)$, with little evidence of heterogeneity (Table 3 and Figure 6). Confined to three studies from North America, the HR was 0.85 (95\% CI: 0.50 to 144) but with more substantial heterogeneity $\left(I^{2}=6 \%\right)$.

\section{Discussion}

This meta-analysis, involving a total of 108,136 PCa cases from 39 observational studies, examined the association of the use of any NSAID with the risk of PCa incidence or mortality. The major finding of the present meta-analysis provides support for the mechanistic hypothesis that aspirin use (including long-term use of more than four years) is inversely related to the risk of $\mathrm{PCa}$ incidence. The association was slightly stronger for advanced $\mathrm{PCa}$ than for total $\mathrm{PCa}$ $(\mathrm{OR}=0.92$ for total $\mathrm{PCa}, \mathrm{OR}=0.81$ for advanced $\mathrm{PCa}) . \mathrm{A}$ cumulative meta-analysis showed that a statistically significant effect of aspirin use on PCa incidence was consistently observed after publication of the 13th trial in 2006. More importantly, aspirin use demonstrated a $14 \%$ decrease in PCa-specific mortality for total PCa compared to non-use. In general, the pooled effects for any NSAIDs, NA-NSAIDs and COX-2 inhibitors demonstrated no 
Table 3 Results of subgroup analyses by outcome type and NSAIDs type

\begin{tabular}{|c|c|c|c|c|c|c|}
\hline \multirow[t]{2}{*}{ Study characteristics } & \multirow{2}{*}{$\begin{array}{l}\text { Number } \\
\text { of studies }\end{array}$} & \multirow[t]{2}{*}{ OR $(95 \% \mathrm{Cl})$} & \multirow[t]{2}{*}{$P_{O R}$ value } & \multirow[t]{2}{*}{ Effect model } & \multicolumn{2}{|c|}{ Heterogeneity } \\
\hline & & & & & $I^{2}(\%)$ & Pvalue \\
\hline \multicolumn{7}{|l|}{ Risk of prostate cancer incidence } \\
\hline \multicolumn{7}{|l|}{ Any NSAIDs } \\
\hline Studies of total prostate cancer & 11 & $0.90(0.75,1.07)$ & 0.25 & Random & 93.5 & $<0.001$ \\
\hline Case-control studies & 8 & $0.97(0.79,1.20)$ & 0.78 & Random & 93.8 & $<0.001$ \\
\hline Cohort studies & 3 & $0.71(0.47,1.07)$ & 0.10 & Random & 81.4 & 0.005 \\
\hline Studies in North America & 6 & $0.73(0.60,0.88)$ & 0.001 & Random & 79.6 & $<0.001$ \\
\hline Studies in Europe & 5 & $1.29(1.25,1.34)$ & $<0.001$ & Fixed & 37.2 & 0.17 \\
\hline Studies of advanced prostate cancer & 5 & $0.86(0.52,1.40)$ & 0.54 & Random & 94.2 & $<0.001$ \\
\hline \multicolumn{7}{|l|}{ Aspirin } \\
\hline Studies of total prostate cancer & 23 & $0.92(0.87,0.97)$ & 0.002 & Random & 66.2 & $<0.001$ \\
\hline Case-control studies & 13 & $0.92(0.85,0.99)$ & 0.040 & Random & 63.7 & 0.001 \\
\hline Cohort studies & 10 & $0.91(0.83,0.99)$ & 0.040 & Random & 71.7 & $<0.001$ \\
\hline Studies from North America & 16 & $0.92(0.86,0.97)$ & 0.003 & Random & 53.7 & 0.006 \\
\hline Studies from Europe & 7 & $0.94(0.82,1.08)$ & 0.40 & Random & 80.7 & $<0.001$ \\
\hline High quality studies & 8 & $0.89(0.81,0.98)$ & 0.022 & Random & 77.2 & $<0.001$ \\
\hline Long-term aspirin use ( $\geq 4$ years) & 8 & $0.88(0.79,0.99)$ & 0.038 & Random & 66.8 & 0.004 \\
\hline Studies of advanced prostate cancer & 13 & $0.81(0.73,0.89)$ & $<0.001$ & Fixed & 23.9 & 0.20 \\
\hline Case-control studies & 7 & $0.84(0.73,0.98)$ & 0.025 & Fixed & 23.7 & 0.18 \\
\hline Cohort studies & 6 & $0.77(0.67,0.89)$ & $<0.001$ & Fixed & 23.5 & 0.26 \\
\hline Studies from North America & 9 & $0.82(0.75,0.89)$ & $<0.001$ & Fixed & 14.0 & 0.32 \\
\hline Studies from Europe & 4 & $0.88(0.75,1.03)$ & 1.22 & Fixed & 48.2 & 0.12 \\
\hline High quality studies & 6 & $0.81(0.72,0.92)$ & 0.002 & Fixed & 38.1 & 0.152 \\
\hline Studies of non-advanced prostate cancer & 6 & $0.96(0.87,1.07)$ & 0.460 & Fixed & 33.6 & 0.177 \\
\hline \multicolumn{7}{|l|}{ Non-aspirin NSAIDs } \\
\hline Studies of total prostate cancer & 17 & $1.01(0.90,1.13)$ & 0.86 & Random & 90.1 & $<0.001$ \\
\hline Case-control studies & 11 & $0.97(0.81,1.17)$ & 0.74 & Random & 93.0 & $<0.001$ \\
\hline Cohort studies & 6 & $1.07(0.95,1.20)$ & 0.25 & Random & 69.6 & 0.006 \\
\hline Studies from North America & 11 & $0.94(0.85,1.05)$ & 0.28 & Random & 68.8 & $<0.001$ \\
\hline Studies from Europe & 6 & $1.18(1.06,1.32)$ & 0.002 & Random & 71.1 & 0.004 \\
\hline Studies of advanced prostate cancer & 9 & $0.99(0.77,1.28)$ & 0.97 & Random & 81.6 & $<0.001$ \\
\hline Studies of non-advanced prostate cancer & 3 & $1.00(0.90,1.12)$ & 0.943 & Fixed & 0.0 & 0.897 \\
\hline \multicolumn{7}{|l|}{ Any $\operatorname{COX} 2$ inhibitors } \\
\hline Studies of total prostate cancer & 5 & $1.10(0.90,1.33)$ & 0.36 & Random & 48.7 & 0.099 \\
\hline Studies of advanced prostate cancer & 3 & $1.20(0.79,1.83)$ & 0.40 & Fixed & 0.0 & 0.87 \\
\hline \multicolumn{7}{|l|}{ Risk of prostate cancer-specific mortality } \\
\hline \multicolumn{7}{|l|}{ Any NSAIDs (including aspirin use alone) } \\
\hline Studies of total prostate cancer & 8 & $1.00(0.68,1.47)$ & 0.99 & Random & 95.3 & $<0.001$ \\
\hline \multicolumn{7}{|l|}{ Aspirin } \\
\hline Studies of total prostate cancer & 6 & $0.86(0.78,0.96)$ & 0.005 & Fixed & 39.2 & 0.15 \\
\hline Studies from North America & 3 & $0.85(0.50,144)$ & 0.55 & Random & 63.8 & 0.063 \\
\hline Studies from Europe & 3 & $0.85(0.76,0.95)$ & 0.005 & Fixed & 12.8 & 0.32 \\
\hline
\end{tabular}

$\mathrm{Cl}$, confidence interval; COX-2, cyclooxygenase enzymes-2; OR, odds ratio. 


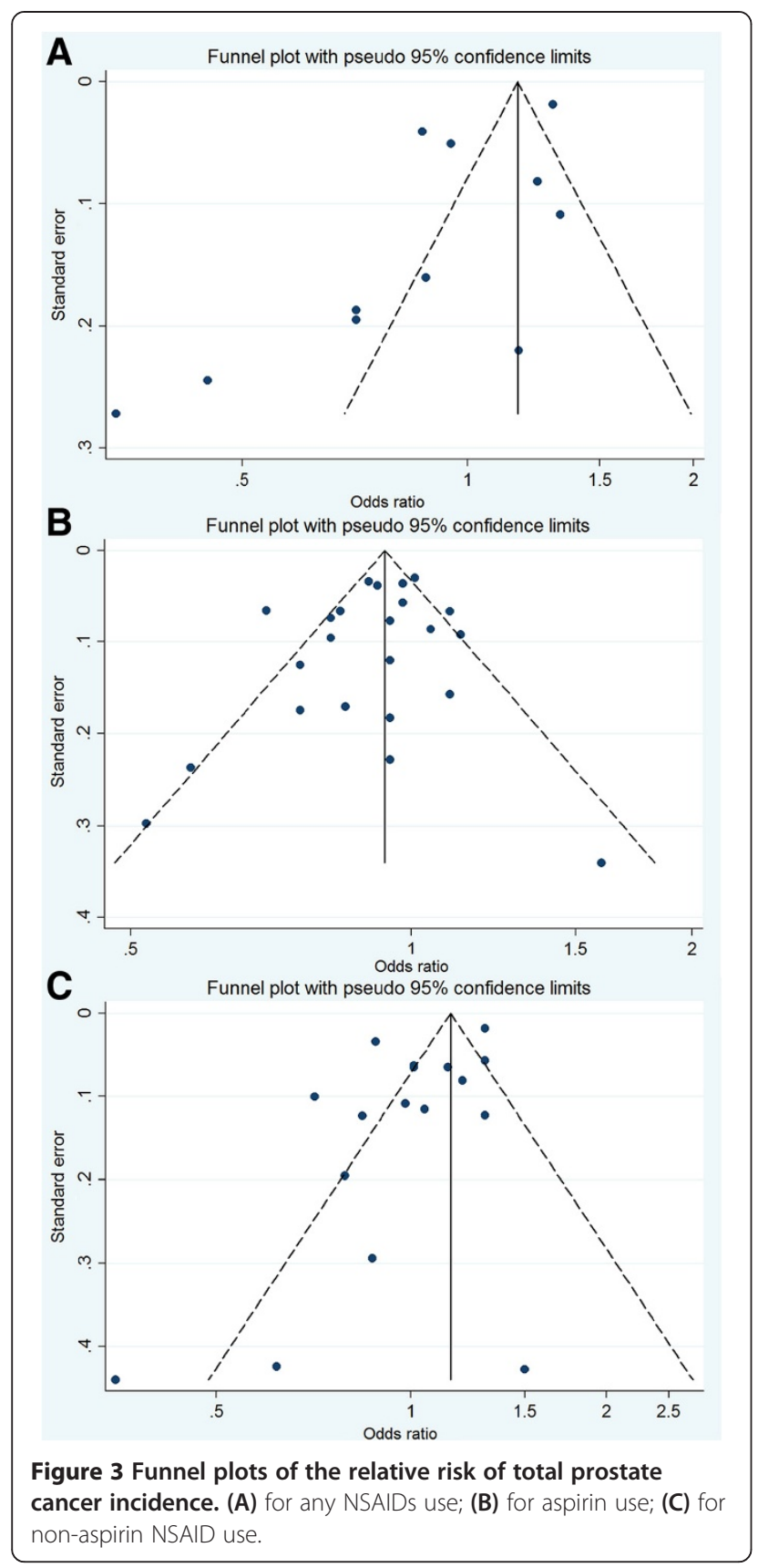

adverse or beneficial effects on PCa development or PCaspecific survival, but the results were not consistent; all the effect estimates varied by geographic region.

There is a long-standing debate about the relationship between NSAID use and cancer. Several reviewed studies discussed the potential chemoprevention effects of NSAID use against tumors at various sites, including breast [57], lung [58] and brain [59], and melanoma [60]. This metaanalysis, with a much larger number of participants than previous meta-analyses $[38,61]$, adds to the previous findings by showing that aspirin use demonstrates a protective effect against $\mathrm{PCa}$. With a larger sample size, increased statistical power could be obtained. In addition, we evaluated whether the association varied by COX-2 inhibitor, long-term aspirin use and study quality, and we investigated whether NSAID use influenced mortality from the disease, issues that were not discussed in the primary meta-analysis. Moreover, the present studies included an approved quality evaluation system; thus, it was more reliable in minimizing potential bias.

There are several proposed mechanisms by which these effects could be explained. Primary laboratory studies have pointed to COX-2 overexpression in PCa tissue [3], and it is well established that increased expression of COX-2 is related to tumor growth [4] and poorer prognosis [5]. NSAIDs inhibit PCa cell growth by reducing the synthesis of prostaglandins by COX enzymes [62], including inducing apoptosis [63], inhibiting cellular proliferation and angiogenesis [64]. Animal and laboratory studies have confirmed the preventive effect of NSAIDs on PCa repeatedly and consistently. In a review of 12 studies, the authors reported that, in all the included studies, all types of NSAIDs exhibited inhibitory effects on PCa development and progression.

In our study, use of aspirin was significantly inversely related to the risks of developing advanced $\mathrm{PCa}$ but not non-advanced $\mathrm{PCa}$, which is difficult to explain. It may possibly be explained by detection bias if aspirin users were more likely to be screened and, therefore, to be diagnosed at an earlier stage. However, this effect may be real. Laboratory studies have suggested that advanced stage PCa may represent heterogeneous etiologies [65] and the mechanism by which aspirin acts on the initiation of poorly-differentiated disease may be distinct from its influence on the development of advanced disease [20]. There was also evidence that NSAIDs evoke tumor regression in gastrointestinal tumors [66], and may have similar effects against cancers of other sites including the prostate. Our findings with regard to the effects of aspirin on disease severity require confirmation in larger studies using unbiased diagnostic approaches.

We postulated that the use of aspirin reduced overall PCa risk. This could have significant implications with respect to the dose, frequency and duration of aspirin use. Unfortunately, most studies lacked information on dosage, frequency and duration of exposure. Although some studies have provided this information, they varied in each trial, resulting in invalid statistical analysis in these groups. In a study by Veitonmaki et al. [37] in 2013, a dose-effect relationship was found, indicating a significant inverse association $(\mathrm{OR}=0.83)$ only among participants who used aspirin at the dosage of 37 to 1,300 defined daily dose (DDD). The other benefit was shown among those who took more than one aspirin pill per day $[23,29,34]$, a low dose $(\leq 75 \mathrm{mg} /$ daily) [27,32], larger doses ( $\geq 325 \mathrm{mg}$ /daily) [26] or more than six tablets/week [20]; nevertheless, other studies found no evidence of a dose-effect $[7,10,17,19,33,35]$ 


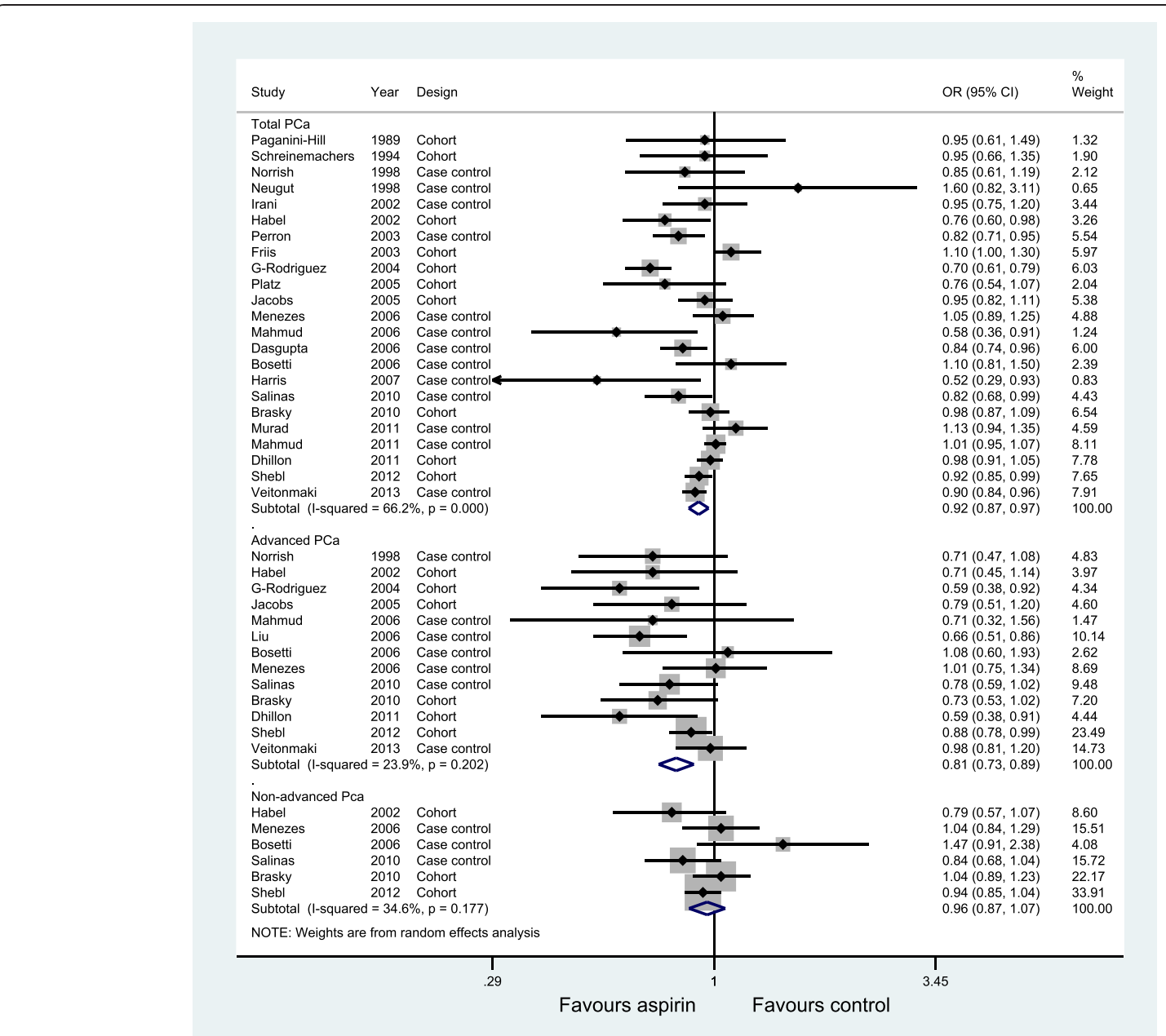

Figure 4 Association between aspirin use and incidence of prostate cancer.

or frequency-effect $[14,16,17]$ relationship. In terms of the duration of aspirin use, we used the available data from eight studies [15,17-20,26,27,32] with durations of more than four years. Our pooled results demonstrated a negative trend of $\mathrm{PCa}$ risk with more than four years of aspirin use.

Considering the high incidence of $\mathrm{PCa}$ and the widespread use of aspirin in the general population, therefore, successful prevention could have a major public health impact. However, physicians should be aware of which subgroups of the population are at high risk for $\mathrm{PCa}$, and the optimal dosage of aspirin, as well as its side effects, should be addressed. It seems that the use of aspirin in clinical prevention still has a long way to go, but, at least, the evidence implies that it is beneficial against the risk of PCa.

Nevertheless, several limitations of this study must be acknowledged. First, heterogeneity was a potential problem when interpreting the results of our analysis. In our metaanalysis, significant heterogeneity was observed in many of the analyses we conducted. Despite stratifying the data into subgroups based on type of outcome, study design, geographic region, quality of study and duration of aspirin use, some heterogeneity was still detected. In fact, it is no surprise given the differences of each study in the definition of drug exposure, information collection methods (for example, questionnaires or medical records), race, age and lifestyle factors of participants, sample size, duration of study follow-up and so on.

Second, as shown in Table 1 and Table 2, the number and content of the adjusted confounders differed among studies, which could have caused some imprecision in the effect estimates. The established risk factors for $\mathrm{PCa}$ are African-American ethnicity and family history of PCa [65]. Most studies adjusted for age and race using multivariate statistical models. Few studies adjusted for family history of PCa. However, researchers do not always make the same decisions concerning confounding factors. We did our best to minimize these confounding biases by choosing the most multivariable adjusted-effect estimates to analyze.

In addition, several sources of bias could have affected our observed associations. First, observational studies have 


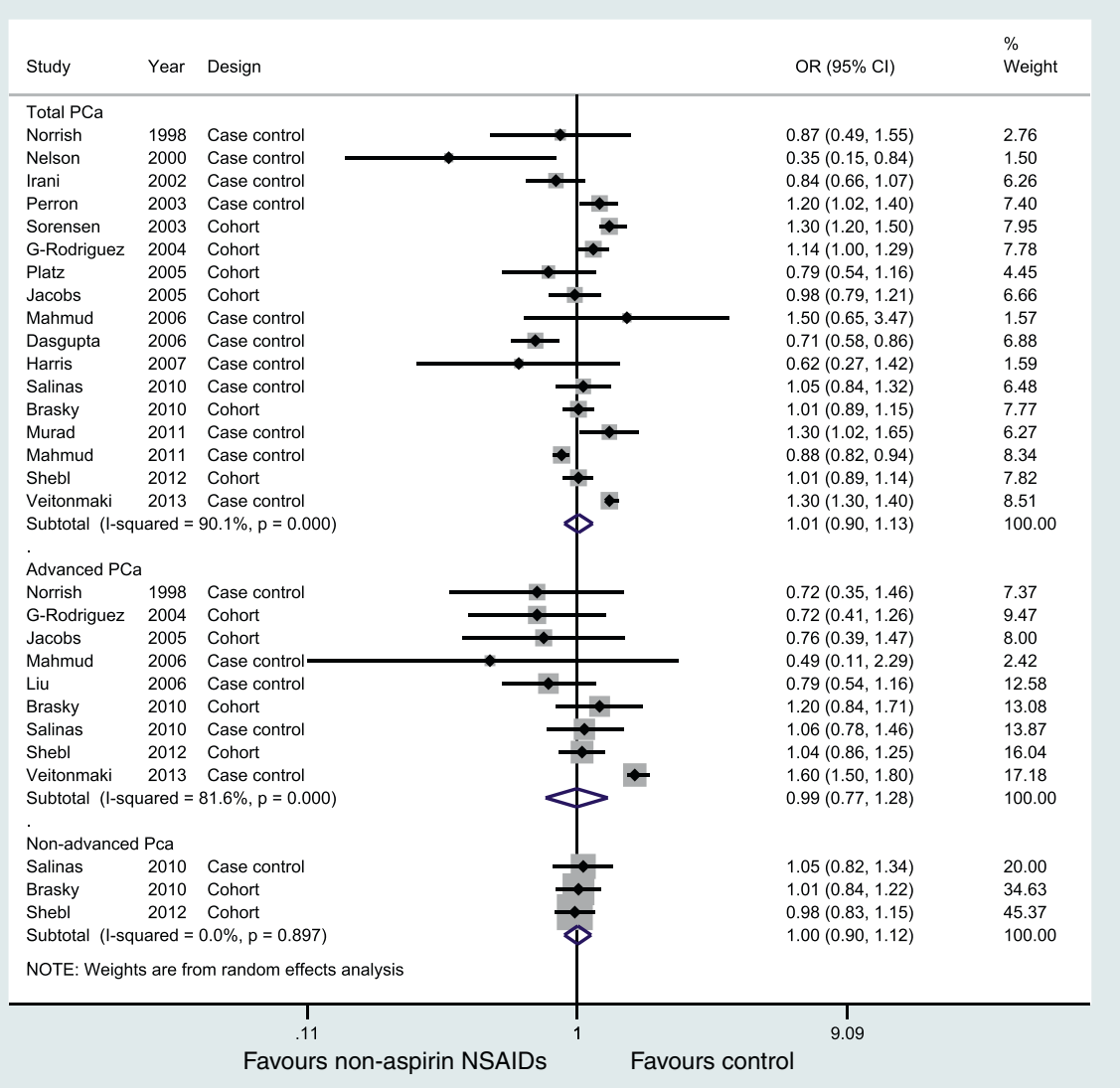

Figure 5 Association between non-aspirin NSAID use and incidence of prostate cancer.

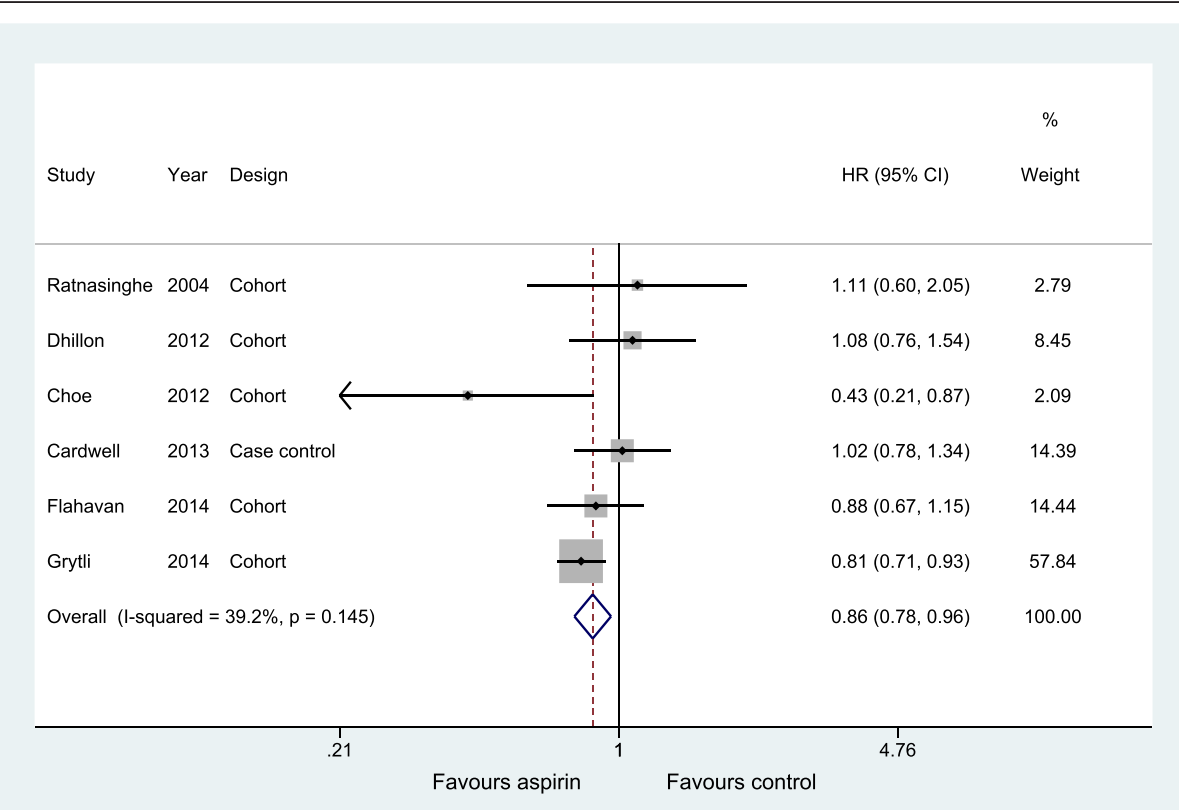

Figure 6 Association between aspirin use and prostate cancer-specific mortality. 
inherent limitations, notably bias and unmeasured confounding. On the other hand, screening and surveillance biases are potentially a major source of systemic error in the reviewed studies. NSAID use may be associated with the socioeconomic status of patients. Thus, NSAID users might maintain healthier lifestyle habits than non-users, which could influence their risk for PCa. Moreover, NSAID users may have easier and more frequent access to preventive healthcare services, such as screening for prostate-specific antigen (PSA), which theoretically could lower the incidence of $\mathrm{PCa}$.

At this stage, randomized controlled trials (RCTs) would be required to evaluate further the relationship between NSAIDs and PCa risk. However, RCTs for this topic could be extremely difficult or even impossible. First, $\mathrm{PCa}$ is rare and mainly occurs in older men; second, too many people in the general population take NSAIDs, especially aspirin, for various important medical reasons. This will render randomization and adherence to the protocol impossible. If one wants to conduct such a trial in younger subjects who do not take NSAIDS, investigators will run into the trouble of having enough end-points (events) given their young age.

\section{Conclusions}

Our current study, based on the available studies and updated data from a previous meta-analysis, supports the hypothesis that aspirin use (including long-term use) provides potential benefits in the reduction of $\mathrm{PCa}$ incidence and PCa-specific mortality. The inverse association was slightly stronger for advanced $\mathrm{PCa}$ than for total $\mathrm{PCa}$, but the effect estimates varied by geographic region. Also unclear is the influence of dose and the frequency of aspirin use on PCa incidence and outcomes. Thus, caution needs to be exercised to ensure that the associated prevention benefits of aspirin outweigh the potential side effects (for example. gastrointestinal bleeding).

\section{Additional files}

Additional file 1: PRISMA 2009 Checklist.
Additional file 2: Review methodology.
Additional file 3: Excluded studies and manually reviewed
publications.
Additional file 4: NOS scores.
Additional file 5: Figure S1. Association between long-term aspirin use
and incidence of total prostate cancer. Figure S2. Cumulative meta-analysis
of 23 studies on the association of aspirin use and total prostate cancer
incidence risk. Figure S3. Association between any COX-2 inhibitor use and
incidence of prostate cancer. Figure S4. Association between any NSAIDs
use and prostate cancer-specific mortality.

\section{Abbreviations}

ASA: aspirin; Cl: confidence interval; COX-2: cyclooxygenase enzymes-2; HR: hazard ratio; NA-NSAIDs: non-aspirin nonsteroidal anti-inflammatory drugs; NOS: Newcastle-Ottawa scale; NSAIDs: nonsteroidal anti-inflammatory drugs; OR: odds ratio; PCa: prostate cancer; RCT: randomized controlled trial; $\mathrm{RR}$ : relative risk.

\section{Competing interests}

The authors declare that they have no competing interests.

\section{Authors' contributions}

$Y L, J C$ and LX conducted the literature search and quality assessment and contributed to the drafting of the manuscript. $Y L$, JW and $T L$ performed data extraction and statistical analysis. YH consulted on statistical analysis. JC and YG critically revised drafts of the manuscript. QX and SL conceived and designed the review, assisted with the inclusion/exclusion criteria, acted as independent assessors and critically revised drafts of the manuscript. All of the authors contributed to the interpretation of data and all of the authors critically revised the manuscript. All of the authors are guarantors for the study. All of the authors read and approved the final manuscript.

\section{Acknowledgments}

We thank Scribendi.com for its linguistic assistance during the preparation of this manuscript.This work was supported by the National Natural Science Foundation of China (No: 81360378). The funders had no role in study design, data collection and analysis, decision to publish, or preparation of the manuscript.

\section{Funding}

This work was supported by the National Natural Science Foundation of China (No: 81360378). The funders had no role in study design, data collection and analysis, decision to publish, or preparation of the manuscript.

\section{Author details}

'Department of Clinical Laboratory, First Affiliated Hospital of Guangx Medical University, Nanning, Guangxi Zhuang Autonomous Region, China. ${ }^{2}$ Department of Gastrointestinal Surgery, First Affiliated Hospital of Guangxi Medical University, Nanning, Guangxi Zhuang Autonomous Region, China. ${ }^{3}$ General Practice School, Guangxi Medical University, Nanning, Guangxi Zhuang Autonomous Region, China.

Received: 24 January 2014 Accepted: 6 March 2014 Published: 28 March 2014

\section{References}

1. Siegel R, Ma J, Zou Z, Jemal A: Cancer statistics. CA Cancer J Clin 2014, 64:9-29.

2. Siegel R, DeSantis C, Virgo K, Stein K, Mariotto A, Smith T, Cooper D, Gansler T, Lerro C, Fedewa S, Lin C, Leach C, Cannady RS, Cho H, Scoppa S, Hachey M, Kirch R, Jemal A, Ward E: Cancer treatment and survivorship statistics, 2012. CA Cancer J Clin 2012, 62:220-241.

3. Gupta S, Srivastava M, Ahmad N, Bostwick DG, Mukhtar H: Over-expression of cyclooxygenase-2 in human prostate adenocarcinoma. Prostate 2000, 42:73-78.

4. Yoshimura R, Sano H, Masuda C, Kawamura M, Tsubouchi Y, Chargui J, Yoshimura N, Hla T, Wada S: Expression of cyclooxygenase-2 in prostate carcinoma. Cancer 2000, 89:589-596.

5. Khor LY, Bae K, Pollack A, Hammond ME, Grignon DJ, Venkatesan VM, Rosenthal SA, Ritter MA, Sandler HM, Hanks GE, Shipley WU, Dicker AP: COX-2 expression predicts prostate-cancer outcome: analysis of data from the RTOG 92-02 trial. Lancet Oncol 2007, 8:912-920.

6. Taketo MM: Cyclooxygenase-2 inhibitors in tumorigenesis (part I). J Natl Cancer Inst 1998, 90:1529-1536.

7. Paganini-Hill A, Chao A, Ross RK, Henderson BE: Aspirin use and chronic diseases: a cohort study of the elderly. BMJ 1989, 299:1247-1250.

8. Schreinemachers DM, Everson RB: Aspirin use and lung, colon, and breast cancer incidence in a prospective study. Epidemiology 1994, 5:138-146.

9. Neugut Al, Rosenberg DJ, Ahsan H, Jacobson JS, Wahid N, Hagan M, Rahman MI, Khan ZR, Chen L, Pablos-Mendez A, Shea S: Association between coronary heart disease and cancers of the breast, prostate, and colon. Cancer Epidemiol Biomarkers Prev 1998, 7:869-873.

10. Norrish AE, Jackson RT, McRae CU: Non-steroidal anti-inflammatory drugs and prostate cancer progression. Int J Cancer 1998, 77:511-515.

11. Irani J, Ravery V, Pariente JL, Chartier-Kastler E, Lechevallier E, Soulie M, Chautard D, Coloby P, Fontaine E, Bladou F, Desgrandchamps F, Haillot O: 
Effect of nonsteroidal anti-inflammatory agents and finasteride on prostate cancer risk. J Urol 2002, 168:1985-1988.

12. Friis S, Sorensen HT, McLaughlin JK, Johnsen SP, Blot WJ, Olsen JH: A population-based cohort study of the risk of colorectal and other cancers among users of low-dose aspirin. Br J Cancer 2003, 88:684-688

13. Sorensen HT, Friis S, Norgard B, Mellemkjaer L, Blot WJ, McLaughlin JK, Ekbom A, Baron JA: Risk of cancer in a large cohort of nonaspirin NSAID users: a population-based study. Br J Cancer 2003, 88:1687-1692.

14. Jacobs EJ, Rodriguez C, Mondul AM, Connell CJ, Henley SJ, Calle EE, Thun MJ: A large cohort study of aspirin and other nonsteroidal anti-inflammatory drugs and prostate cancer incidence. J Nat/ Cancer Inst 2005, 97:975-980.

15. Platz EA, Rohrmann S, Pearson JD, Corrada MM, Watson DJ, De Marzo AM, Landis PK, Metter EJ, Carter HB: Nonsteroidal anti-inflammatory drugs and risk of prostate cancer in the Baltimore Longitudinal Study of Aging. Cancer Epidemiol Biomarkers Prev 2005, 14:390-396.

16. Bosetti C, Talamini R, Negri E, Franceschi S, Montella M, La Vecchia C: Aspirin and the risk of prostate cancer. Eur J Cancer Prev 2006, 15:43-45.

17. Menezes RJ, Swede H, Niles R, Moysich KB: Regular use of aspirin and prostate cancer risk (United States). Cancer Causes Control 2006, 17:251-256.

18. Jacobs EJ, Thun MJ, Bain EB, Rodriguez C, Henley SJ, Calle EE: A large cohort study of long-term daily use of adult-strength aspirin and cancer incidence. J Natl Cancer Inst 2007, 99:608-615.

19. Brasky TM, Velicer CM, Kristal AR, Peters U, Potter JD, White E: Nonsteroida anti-inflammatory drugs and prostate cancer risk in the VITamins And Lifestyle (VITAL) cohort. Cancer Epidemiol Biomarkers Prev 2010, 19:3185-3188

20. Dhillon PK, Kenfield SA, Stampfer MJ, Giovannucci EL: Long-term aspirin use and the risk of total, high-grade, regionally advanced and lethal prostate cancer in a prospective cohort of health professionals, 1988-2006. Int J Cancer 2011, 128:2444-2452.

21. Vinogradova Y, Coupland C, Hippisley-Cox J: Exposure to cyclooxygenase-2 inhibitors and risk of cancer: nested case-control studies. $\mathrm{Br} J$ Cancer 2011, 105:452-459.

22. Kopp TI, Friis S, Christensen J, Tjonneland A, Vogel U: Polymorphisms in genes related to inflammation, NSAID use, and the risk of prostate cancer among Danish men. Cancer Genet 2013, 206:266-278.

23. Nelson JE, Harris RE: Inverse association of prostate cancer and non-steroidal anti-inflammatory drugs (NSAIDs): results of a case-control study. Oncol Rep 2000, 7:169-170.

24. Habel LA, Zhao W, Stanford JL: Daily aspirin use and prostate cancer risk in a large, multiracial cohort in the US. Cancer Causes Control 2002, 13:427-434.

25. Roberts RO, Jacobson DJ, Girman CJ, Rhodes T, Lieber MM, Jacobsen SJ: A population-based study of daily nonsteroidal anti-inflammatory drug use and prostate cancer. Mayo Clin Proc 2002, 77:219-225.

26. Perron L, Bairati I, Moore L, Meyer F: Dosage, duration and timing of nonsteroidal antiinflammatory drug use and risk of prostate cancer. Int J Cancer 2003, 106:409-415.

27. Garcia Rodriguez LA, Gonzalez-Perez A: Inverse association between nonsteroidal anti-inflammatory drugs and prostate cancer. Cancer Epidemiol Biomarkers Prev 2004, 13:649-653.

28. Dasgupta K, Di Cesar D, Ghosn J, Rajan R, Mahmud S, Rahme E: Association between nonsteroidal anti-inflammatory drugs and prostate cancer occurrence. Cancer J 2006, 12:130-135.

29. Liu X, Plummer SJ, Nock NL, Casey G, Witte JS: Nonsteroidal antiinflammatory drugs and decreased risk of advanced prostate cancer: modification by lymphotoxin alpha. Am J Epidemiol 2006, 164:984-989.

30. Mahmud SM, Tanguay S, Begin LR, Franco EL, Aprikian AG: Non-steroidal anti-inflammatory drug use and prostate cancer in a high-risk population. Eur J Cancer Prev 2006, 15:158-164.

31. Harris RE, Beebe-Donk J, Alshafie GA: Cancer chemoprevention by cyclooxygenase 2 (COX-2) blockade: results of case control studies. Subcell Biochem 2007, 42:193-212

32. Salinas CA, Kwon EM, FitzGerald LM, Feng Z, Nelson PS, Ostrander EA, Peters $U$, Stanford JL: Use of aspirin and other nonsteroidal antiinflammatory medications in relation to prostate cancer risk. Am J Epidemiol 2010, 172:578-590.

33. Mahmud SM, Franco EL, Turner D, Platt RW, Beck P, Skarsgard D, Tonita J, Sharpe C, Aprikian AG: Use of non-steroidal anti-inflammatory drugs and prostate cancer risk: a population-based nested case-control study. PLoS One 2011, 6:e16412.
34. Shebl FM, Sakoda LC, Black A, Koshiol J, Andriole GL, Grubb R, Church TR, Chia D, Zhou C, Chu LW, Huang WY, Peters U, Kirsh VA, Chatterjee N, Leitzmann MF, Hayes RB, Hsing AW: Aspirin but not ibuprofen use is associated with reduced risk of prostate cancer: a PLCO study. Br J Cancer 2012, 107:207-214.

35. Langman MJ, Cheng KK, Gilman EA, Lancashire RJ: Effect of anti-inflammatory drugs on overall risk of common cancer: case-control study in general practice research database. BMJ 2000, 320:1642-1646.

36. Murad AS, Down L, Davey Smith G, Donovan JL, Athene Lane J, Hamdy FC, Neal DE, Martin RM: Associations of aspirin, nonsteroidal anti-inflammatory drug and paracetamol use with PSA-detected prostate cancer: findings from a large, population-based, case-control study (the ProtecT study). Int J Cancer 2011, 128:1442-1448.

37. Veitonmaki T, Tammela TL, Auvinen A, Murtola TJ: Use of aspirin, but not other non-steroidal anti-inflammatory drugs is associated with decreased prostate cancer risk at the population level. Eur J Cancer 2013, 49:938-945.

38. Mahmud SM, Franco EL, Aprikian AG: Use of nonsteroidal anti-inflammatory drugs and prostate cancer risk: a meta-analysis. Int I Cancer 2010, 127:1680-1691.

39. Flahavan EM, Bennett K, Sharp L, Barron TI: A cohort study investigating aspirin use and survival in men with prostate cancer. Ann Oncol 2014, 25:154-159.

40. Grytli HH, Fagerland MW, Fossa SD, Tasken KA: Association between use of beta-blockers and prostate cancer-specific survival: acohort study of 3561 prostate cancer patients with high-risk or metastatic disease. Eur Urol 2014, 65:635-641.

41. Cardwell CR, Flahavan EM, Hughes CM, Coleman HG, O'Sullivan JM, Powe $D G$, Murray LJ: Low-dose aspirin and survival in men with prostate cancer: a study using the UK Clinical Practice Research Datalink. Cancer Causes Control 2013, 24:33-43.

42. Dhillon PK, Kenfield SA, Stampfer MJ, Giovannucci EL, Chan JM: Aspirin use after a prostate cancer diagnosis and cancer survival in a prospective cohort. Cancer Prev Res (Phila) 2012, 5:1223-1228.

43. Choe KS, Cowan JE, Chan JM, Carroll PR, D'Amico AV, Liauw SL: Aspirin use and the risk of prostate cancer mortality in men treated with prostatectomy or radiotherapy. J Clin Oncol 2012, 30:3540-3544.

44. Stock DC, Groome PA, Siemens DR, Rohland SL, Song Z: Effects of non-selective non-steroidal anti-inflammatory drugs on the aggressiveness of prostate cancer. Prostate 2008, 68:1655-1665.

45. Ratnasinghe LD, Graubard BI, Kahle L, Tangrea JA, Taylor PR, Hawk E: Aspirin use and mortality from cancer in a prospective cohort study. Anticancer Res 2004, 24:3177-3184.

46. Lipworth L, Friis S, Blot WJ, McLaughlin JK, Mellemkjaer L, Johnsen SP, Norgaard B, Olsen JH: A population-based cohort study of mortality among users of ibuprofen in Denmark. Am J Ther 2004, 11:156-163.

47. Moher D, Liberati A, Tetzlaff J, Altman DG, PRISMA Group: Preferred reporting items for systematic reviews and meta-analyses: the PRISMA statement. PLOS Med 2009, 6:e1000097.

48. Wells G, Shea B, O'Connell D, Peterson J, Welch V, Losos M, Tugwell P: The Newcastle-Ottawa Scale (NOS) for assessing the quality of nonrandomised studies in meta-analyses. 2009. Available at: http://www.ohri.ca/programs/ clinical_epidemiology/oxford.asp.

49. Mantel N, Haenszel W: Statistical aspects of the analysis of data from retrospective studies of disease. J Natl Cancer Inst 1959, 22:719-748.

50. DerSimonian R, Laird N: Meta-analysis in clinical trials. Control Clin Trials 1986, 7:177-188.

51. Zhang J, Yu KF: What's the relative risk? A method of correcting the odds ratio in cohort studies of common outcomes. JAMA 1998, 280:1690-1691.

52. Higgins JP, Thompson SG, Deeks JJ, Altman DG: Measuring inconsistency in meta-analyses. BMJ 2003, 327:557-560.

53. Higgins JP, Thompson SG: Quantifying heterogeneity in a meta-analysis. Stat Med 2002, 21:1539-1558.

54. Begg CB, Mazumdar M: Operating characteristics of a rank correlation test for publication bias. Biometrics 1994, 50:1088-1101.

55. Egger M, Davey Smith G, Schneider M, Minder C: Bias in meta-analysis detected by a simple, graphical test. BMJ 1997, 315:629-634.

56. Copas J, Shi JQ: Meta-analysis, funnel plots and sensitivity analysis. Biostatistics 2000, 1:247-262.

57. Luo T, Yan HM, He P, Luo Y, Yang YF, Zheng H: Aspirin use and breast cancer risk: a meta-analysis. Breast Cancer Res Treat 2012, 131:581-587.

58. Xu JL, Yin ZQ, Gao W, Liu LX, Wang RS, Huang PW, Yin YM, Liu P, Yu RB, Shu YQ: Meta-analysis on the association between nonsteroidal 
anti-inflammatory drug use and lung cancer risk. Clin Lung Cancer 2012, 13:44-51.

59. Liu Y, Lu Y, Wang J, Xie L, Li T, He Y, Peng Q, Qin X, Li S: Association between non-steroidal anti-inflammatory drug use and brain tumour risk: a meta-analysis. Br J Clin Pharmacol 2013. doi:10.1111/bcp.12311.

60. Li S, Liu Y, Zeng Z, Peng Q, Li R, Xie L, Qin X, Zhao J: Association between non-steroidal anti-inflammatory drug use and melanoma risk: a meta-analysis of 13 studies. Cancer Causes Control 2013, 24:1505-1516.

61. Mahmud S, Franco E, Aprikian A: Prostate cancer and use of nonsteroidal anti-inflammatory drugs: systematic review and meta-analysis. Br J Cancer 2004, 90:93-99.

62. Wang D, Dubois RN: Prostaglandins and cancer. Gut 2006, 55:115-122.

63. Hsu AL, Ching TT, Wang DS, Song X, Rangnekar VM, Chen CS: The cyclooxygenase-2 inhibitor celecoxib induces apoptosis by blocking Akt activation in human prostate cancer cells independently of Bcl-2. J Biol Chem 2000, 275:11397-11403.

64. Kirschenbaum A, Liu X, Yao S, Levine AC: The role of cyclooxygenase-2 in prostate cancer. Urology 2001, 58:127-131.

65. Giovannucci E, Liu Y, Platz EA, Stampfer MJ, Willett WC: Risk factors for prostate cancer incidence and progression in the health professionals follow-up study. Int J Cancer 2007, 121:1571-1578.

66. Dempke W, Rie C, Grothey A, Schmoll HJ: Cyclooxygenase-2: a novel target for cancer chemotherapy? J Cancer Res Clin Oncol 2001, 127:411-417.

doi:10.1186/1741-7015-12-55

Cite this article as: Liu et al:: Effect of aspirin and other non-steroidal anti-inflammatory drugs on prostate cancer incidence and mortality: a systematic review and meta-analysis. BMC Medicine 2014 12:55.

\section{Submit your next manuscript to BioMed Central and take full advantage of:}

- Convenient online submission

- Thorough peer review

- No space constraints or color figure charges

- Immediate publication on acceptance

- Inclusion in PubMed, CAS, Scopus and Google Scholar

- Research which is freely available for redistribution 